\title{
Minority internship/scholarship in library and information science
}

\author{
By Curtis Kendrick \\ Former Head, Circulation \\ SUNY Stony Brook
}

\section{Joyce Clinkscales}

Head, Music Library

SUNY Stony Brook

\author{
Jacob Lipkind \\ Assistant Head, Reference \\ SUNY Stony Brook \\ Amelia Salinero \\ Cataloger \\ SUNY Stony Brook
}

and Hélène Volat-Shapiro

Assistant Head, Bibliographic Services

SUNY Stony Brook

\section{Institutional commitment to the general problem of underrepresentation of minorities in academia.}

$\mathbf{T}$

he Minority Internship/Scholarship in Library and Information Sciences (MILIS $)^{1}$ program is designed for minority ${ }^{2}$ undergraduate students at the State University of New York (SUNY) at Stony Brook who have demonstrated leadership potential and are interested in pursuing a career in librarianship. Students accepted into the MILIS program participate in a paid internship in the library during their senior year and receive a full scholarship from SUNY at

\footnotetext{
${ }^{1}$ The name and acronym for this program were developed by Danna Bell, formerly special collections librarian at SUNY Stony Brook, now librarian for the National Association for the Advancement of Colored People.

${ }^{2}$ Asian American, African American, Hispanic American, Native American.
}

Albany's Graduate School of Information Science and Policy upon acceptance into its master's program.

\section{Why MILIS is necessary}

Within the United States the minority population is growing at a faster rate than the population as a whole. Projections indicate a significant growth through the first quarter of the next century in the percentage of the college age population comprising minorities. ${ }^{3}$

While the proportion of minorities is expected to

${ }^{3}$ 1986-87 Fact Book on Higher Education (Washington: American Council on Higher Education, 1987). 


\section{The Ultimate Acquisition Management Tool}
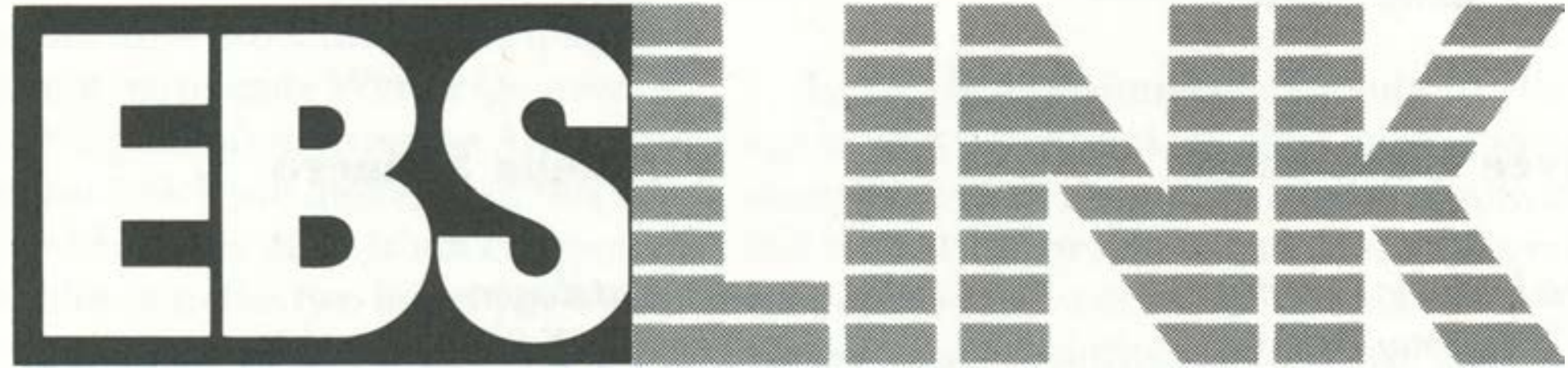

EBS announces a software package designed to serve the professional librarian's needs-NOT THE NEEDS OF YOUR VENDOR. EBS LINK isn't just an ordering device or a list of your vendor's inventory; EBS LINK is a management tool that will HELP YOU THROUGHOUT the acquisitions process.

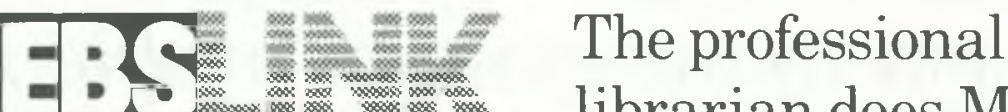 \\ L librarian does MORE}

than order books. We realize that and we created EBS LINK to be an ACQUISITIONS MANAGEMENT TOOL. It keeps track of all your budgets, retrieves information the way you should have it, and helps you to be a more efficient librarian.

Every library can use an extra arm or two in its acquisitions department. EBS LINK can help you make EBS your extra arm.

\section{Z:R}

For information about obtaining EBS LINK at no charge, call:

\section{1-800-899-0290}

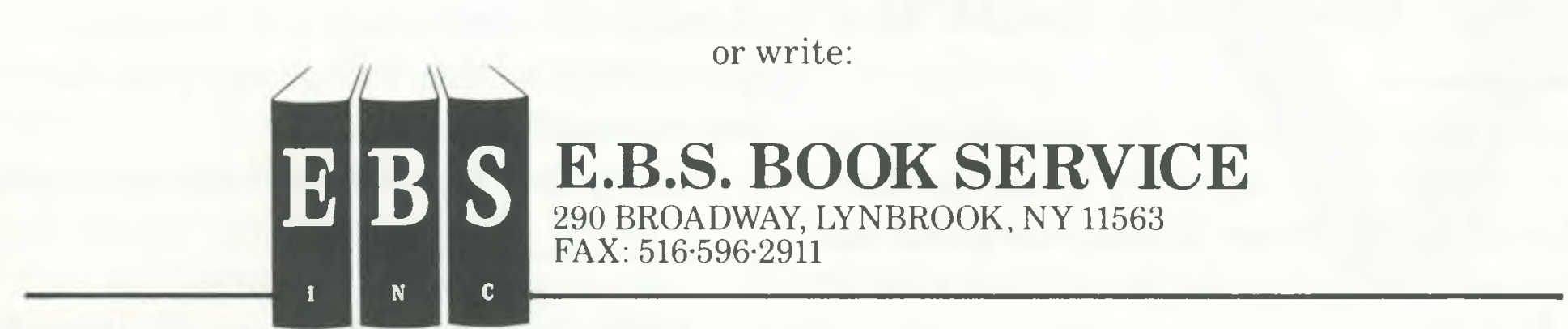


continue to grow over the next few decades, the proportion of minority librarians is decreasing. Between 1979 and 1984 there was a 40\% decrease (369 to 221) in the number of minorities graduating each year from master's programs in library and information science. ${ }^{4}$ It is clear that the profession is not doing an adequate job of attracting minority students to pursue careers in librarianship. In order to grasp the full extent of this problem it is helpful to observe how librarianship compares with other disciplines. During 1986/87, 10.6\% of master's degrees awarded in all disciplines were awarded to minority students; in the field of librarianship only $7.7 \%$ of the master's degrees were awarded to minorities. ${ }^{5}$

\section{Why at Stony Brook and Albany?}

The MILIS program has afforded Stony Brook and Albany the opportunity to assume a leadership role in a vital area within the profession. After seeing that such a program is viable, other institutions within the SUNY system have expressed an interest in pursuing similar programs on their own campuses. The fact that Stony Brook and Albany are public institutions is important because minority students are more likely to attend public institutions than private colleges or universities; $79 \%$ of the African American, 83\% of Asian American, and $77 \%$ of Native American students attend public institutions. $^{6}$

Stony Brook has demonstrated an institutional commitment to the general problem of underrepresentation of minorities in academia. In 1987 Stony Brook hosted a national conference entitled "The Role of Faculty in Meeting the National Need for African American, American Indian, and Latino Scholars," as well as a local conference entitled "To Form a More Perfect Campus: Addressing Underrepresentation of Blacks, Hispanics and American Indians in Graduate Education." Former provost Jerry Schubel commented at the local conference that "we cannot hope to hire black-or Hispanic or American Indian-faculty members if there are no black-or Hispanic or American Indian-graduate students. At a time

${ }^{4}$ Lorene B. Brown, "A Crisis in Librarianship: The Decline in the Number of Minorities Entering the Profession Since 1979." Paper presented at the meeting of the Black Caucus of the American Library Association, Chicago, January 19, 1986.

${ }^{5}$ Digest of Education Statistics 1989. Table 217.

6"General Data on Minorities in Higher Education," in Minority Student Enrollments in Higher Education (Garrett Park Press, 1987). No figures provided for Hispanic enrollment in public colleges and universities. when the percentage of black graduate students is lower now than it was ten years ago, we must make strenuous efforts to identify talented students early, and give them whatever intellectual, emotional or financial encouragement they need to continue their education."7 The MILIS program is consistent with the provost's vision of how to form a more perfect campus as it identifies talented students (the application/selection process), provides intellectual encouragement (the internship), emotional encouragement (the mentoring component), and perhaps most importantly, financial encouragement (the scholarship).

\section{Program background}

In July 1988 Curtis Kendrick, head of the Circulation Department, presented to the director of libraries a proposal to implement an internship/ scholarship program aimed at recruiting minority undergraduates to the field of library and information sciences. Stony Brook does not offer a graduate degree in librarianship, so contact was established with Richard Halsey, dean of the School of Information Science and Policy at SUNY Albany, which resulted in Albany's cosponsorship of the program. As cosponsor, Albany is responsible for identifying funds to grant full scholarships to program participants who are accepted into SUNY at Albany's School of Information Science and Policy.

Accepting responsibility for the internship component of MILIS, John Brewster Smith, director of libraries and dean at Stony Brook, appointed the MILIS Committee and charged the committee with the development and management of all aspects of the MILIS program. This included developing the program structure (including a method for reviewing the program), publicizing the program and recruiting applicants, establishing selection criteria, reviewing applications, interviewing finalists, and submitting recommendations for interns to the director of libraries. The MILIS Committee developed a timetable for the program's first year of operation to make sure that publicity, recruitment and selection were accomplished and also to develop the content of the internship.

\section{Publicity and recruitment}

Advertising the MILIS program and recruiting applicants were the first tasks of the MILIS Committee. An attractive brochure was created and displayed in various departments of the library, particularly in public services areas. Along with the brochure the committee designed application and

\footnotetext{
${ }^{7}$ J. R. Schubel, Academic News 6 (January-
} March 1988). 
POPULATION OF THE UNITED STATES, AGE 18-24

\begin{tabular}{ccc}
\hline \hline Year & Minority & Non-minority \\
\hline 1980 & $15.7 \%$ & $84.3 \%$ \\
2000 & $19.3 \%$ & $80.7 \%$ \\
2025 & $23.1 \%$ & $76.9 \%$ \\
\hline
\end{tabular}

recommendation forms to be submitted by the end of the spring semester. ${ }^{8}$

Once the brochure and forms were ready, a publicity distribution list was established, to be updated each year, which includes minority organizations, university offices, particularly those serving undergraduates, local public libraries and Long Island library associations. The 43 names on the distribution list were sent brochures and application and recommendation forms along with a cover letter. Simultaneously, a publicity release was written and distributed to the campus newspapers early in the spring semester.

\section{Selection of the first intern}

One of the charges to the MILIS committee was to recommend interns for the program to the director of libraries. The application form developed by the committee was intended to solicit an applicant's interest in the MILIS program and in librarianship, as well as any extracurricular work, volunteer activities and special skills. A brief essay on the applicant's experiences with libraries and librarians was required, primarily to help the committee assess the applicant's writing skills. Each applicant was also required to submit three letters of recommendation and a course transcript.

Once all the application materials were received, the MILIS Committee reviewed the applications and, in preparing to conduct interviews, developed the following selection guidelines.

During the first year of the MILIS program the committee interviewed one candidate and, after serious discussions and review of her file, recommended to the director of libraries that she be invited to participate in the MILIS program. In September 1989 Bangsook Lee was appointed the first intern in the MILIS program.

\section{Program details}

Cataloging and reference formed the two main areas of the internship, with a semester dedicated to each of them. After consultation with the intern,

${ }^{8}$ For a copy of the brochure and forms contact: Judith Kaufman, Personnel and Development Librarian, Melville Library, State University of New York, Stony Brook, NY 11794-3300. the winter intersession period was devoted to music librarianship, a strong interest of hers. The internship schedule required fifteen hours per week at a pay rate of $\$ 6.00$ per hour, a wage approximately $35 \%$ higher than the wage normally provided to undergraduate student assistants in the library. The purpose of the higher wage was to draw a clear distinction between the intern and student assistants. When the intern "worked" within a department, the goal was to learn how the department operated and the types of problems and issues that arose, and to acquire a basic knowledge of the theoretical and practical aspects of particular areas of librarianship.

With any new program there is naturally some concern about how the program will affect other library operations. It was also important for the Stony Brook library administration to keep SUNY at Albany informed. To meet those needs, the MILIS Committee communicated regularly with the director of libraries about the program's progress and developed a syllabus for each semester (see Appendices A and B).

\section{Cataloging component}

Amelia Salinero, cataloger, developed the syllabus for the cataloging component of the internship. In order to go beyond the cataloging of monographs she engaged other members of the Cataloging Department to provide training in the cataloging of maps and music materials. The Serials Department also participated in order to give the intern experience in serials cataloging.

The cataloging syllabus was organized into thirteen weeks. The first two weeks provided an overview of library operations and an introduction to theoretical and practical aspects of cataloging. The third through fifth weeks were dedicated to main entry, descriptive cataloging and monographic series fields. Weeks six and seven covered subject cataloging, followed by a week for added entries. This total of eight weeks was designed to complete the training in the cataloging of monographs. One week dedicated to maps cataloging, two weeks to music and two weeks to serials cataloging completed the one semester cataloging component of the internship.

Lois Mai Chan's book, Cataloging and Classification: An Introduction (New York, 1981), was 
introduced in the first week and used throughout the semester. While learning subject cataloging the intern was introduced to the Library of Congress Subject Headings to validate specific subject headings and to the Library of Congress Classification Schedules to match classification numbers to subjects. The intern studied the Library of Congress classification scheme arrangement for individual authors by following a prolific literary author through the shelflist cards and noting the different ordering possibilities according to type of work: collected works, selections, individual works and works of criticism about the author.

Hands-on work began in the first week with general bibliographic and authority searching in the OCLC and RLIN online databases. Beginning in the second week the intern filled out complete cataloging forms for books with Library of Congress Cataloging-in-publication (CIP). By the fourth week the intern started to help with actual online copy cataloging under appropriate supervision.

Although the syllabus seemed realistic and sensible, the need for flexibility soon became apparent. Schedule adjustments were made because the intern progressed more rapidly than was anticipated, her needs to prepare for tests and other class requirements had to be given priority, and the supervising staff had to accommodate their own professional responsibilities. During the first stages of the cataloging component Salinero worked closely with the intern, but the amount of time spent working directly with the intern dropped off as the semester progressed. The intern's desk was in front of Salinero's, so if questions arose they could easily be asked, but the intern worked more and more independently as time went on.

\section{Reference component}

During the spring semester the MILIS intern was trained to assist at the Main Library reference desk under the direction of Jacob Lipkind, assistant head of the Reference Department. She was trained to answer directional questions, holdings questions for known titles, and some ready reference questions such as finding zip codes, plot

\section{MASTER'S DEGREES AWARDED}

All Disciplines

Lib./Info. Science

$\begin{array}{lll}\text { Asian American } & 3.0 \% & 2.4 \% \\ \text { African American } & 4.8 \% & 3.8 \% \\ \text { Hispanic American } & 2.4 \% & 1.3 \% \\ \text { Native American } & 0.4 \% & 0.2 \%\end{array}$

TOTAL

$10.6 \%$

$7.7 \%$ summaries, and the addresses of publishers or colleges. The intern worked at the reference desk as a second or sometimes third person, and referred more difficult questions to the reference librarian on duty.

Most of the reference training occurred during the first five to six weeks of the semester, as described in the syllabus in Appendix B. During the training period Lipkind worked intensively with the intern. To provide concrete training and to help improve reference collections and services, the intern also participated in some special projects, including inventorying and updating the college guide and financial aid collections, and determining and noting call numbers for titles indexed in reference sources.

\section{Music librarianship component}

The intern elected to participate in a special unit on music librarianship during the four intersession weeks. This part of the program was supervised by Joyce Clinkscales, head of the Music Library, who designed it in consultation with the MILIS Committee, which wanted the intern to have both learning and working experiences, including a special project. Because of the short period of time involved, the focus was limited to reference and bibliography so that the committee's goals could be met. In order to foster a critical attitude and an analytical approach toward reference materials, the intern was assigned selected reviews and essays to read and discuss with the supervisor. A survey of basic reference sources included sets of simulated reference questions which the intern answered by searching through prescribed groups of sources. As her project she chose to assess the library's holdings of printed music for the chamber music combination of flute and violoncello (instruments which are important in the Music Department program). She compiled a list of compositions held by the library and identified a substantial number of additional works which the library will purchase to enhance holdings in this area. An effort was made to expose her to other facets of music library work besides reference and bibliography. She worked with a cataloger to learn some of the special aspects of music cataloging. In addition, Clinkscales helped her gain an overview of the types of materials and services in music libraries, the various administrative structures possible, and the different types of music libraries that exist.

The formal structure of the components of the MILIS program provided the supervising librarians, the MILIS Committee, the library administration, and the intern with a clear delineation of the aspects of librarianship to be surveyed by the program. There was a natural tension, however, between the need to adhere to the program and the 
need to be flexible. Because much of the program involved one-to-one instruction, supervising librarians had latitude to emphasize certain facets over others, to adjust the amount of time spent on particular areas, or to reorganize the structure of the components to respond to day-to-day realities.

\section{Mentoring}

The design of the MILIS program called for one librarian to serve as mentor to the intern for the academic year. The mentor's role was to meet regularly with the intern in order to provide information and guidance about matters related to work assignments and the intern's academic and professional careers. Specific responsibilities, as defined by the MILIS Committee, were to assist the intern with preparations for the Graduate Record Examination and with the application to SUNY at Albany; to encourage the intern to read professional journals and other selected materials; to encourage her to improve any areas of weakness, such as writing, mathematics, or computer literacy; and to work with other librarians to develop a special project for the intern.

Because Bangsook Lee had worked as a student assistant in the Music Library and had indicated an interest in music librarianship as a career, the MILIS Committee asked Clinkscales to serve as mentor. The intern and mentor met at least every two weeks during the earlier stages of the program, and somewhat less frequently as the year progressed. Meetings were scheduled during the intern's work time. As would be expected in any formal or informal mentoring process, in addition to counseling, the mentor's central function was to provide information and encouragement. The intern was interested in academic librarianship, but needed to know what other types of careers in librarianship were possible. She wanted help in identifying and evaluating graduate schools that she might want to consider in addition to SUNY at
Albany. Predictably enough, she tended to become overwhelmed at times by the complexity of library operations and needed reassurance that she would gradually absorb the basic procedures and that it was not necessary to understand everything before beginning library school. In the mentor's opinion, the times scheduled specifically for review and discussion of the intern's activities proved valuable. Many of the matters discussed were relatively minor and might never have been brought up had it been left to the intern to request meetings when she felt she needed them. Regular meetings also provided feedback on the program. The mentor reported on the intern's progress during meetings of the MILIS committee.

\section{Evaluation and certificate of completion}

The agreement between SUNY at Stony Brook and SUNY at Albany requires that Dean Smith from Stony Brook report on the progress of each intern to Dean Halsey at Albany. This progress report may serve as a recommendation for the intern's application to the graduate program. It should be noted that the interns are expected to go through the formal application procedure to Albany, including taking the GRE test. Furthermore, the interns are not committed to attending Albany; if another institution better matches their needs, they may apply to that institution.

In late February 1990 the MILIS Committee reported to the director of libraries on the progress of Bangsook Lee. The report was quite favorable and focused on the activities in which the intern had engaged in during the program. This report was forwarded to Albany to be reviewed along with the remainder of Lee's application. (The intern was accepted into the SUNY at Albany Graduate School of Information Science and Policy as well as two other library schools.)

Finally, during the last week of classes, the MILIS Committee held a luncheon in honor of the

\section{MILIS SELECTION CRITERIA}

Criteria

Academic performance

Enthusiasm

Communication skills

Interest in/capability for librarianship

Sense of responsibility
Measurement Instruments

GPA, coursework, recommendations

Extra-curricular, volunteer or work activities content of essay, recommendations, interview

Writing style, interview

Content of essay, recommendations, interview

Recommendations, coursework, GPA, work experiences 
intern at which she was presented with a certificate of completion of the MILIS program.

\section{Future enhancements}

Since this was the first year of the MILIS program the MILIS Committee had to limit its energy to the most essential components of the program. However, the committee discussed several other activities that would enhance the internship considerably and will probably be implemented in future years. The committee has already received approval from the library faculty to introduce future interns at a library faculty meeting early in the internship in order to acquaint the library faculty with the intern and also to emphasize the importance of the program to the faculty. (Another library group, the Library Staff Association, invited this year's intern to attend the annual winter holiday party, but she was unable to attend.)

Moving outside the library, the committee would like the intern to attend a professional meeting or conference, if problems of expense and timing can be solved, in order to be exposed to wider professional issues. A likely candidate is the annual conference of SUNYLA, the State University of New York Librarian Association which is held in late spring. Another proposal is a trip to SUNY at Albany to witness firsthand what the campus and classes are like.

From the inception of the MILIS Program, Stony Brook's library administration has suggested that external funding for the program might be possible. As a higher education program focused on minority students it may be possible to identify corporate or government sponsorship. To date the MILIS Committee has not actively pursued external funding, but now that the program structure is established this and other enhancements may be explored.

\section{Conclusion}

The American Library Association's Office for Library Personnel Resources has identified three main difficulties in recruiting minorities to librarianship: 1) problems in identifying candidates; 2) lack of scholarship money; and 3) competition with other more rewarding occupations. The MILIS program responds to the first two of these.

Although there has been a lot of discussion within the profession about the problem of recruiting minorities to librarianship, these discussions have not resulted in any measurable improvements; in fact, the situation is deteriorating. As implemented at Stony Brook, Albany, and elsewhere within the SUNY system, the MILIS program can have a positive effect on recruiting minorities to the profession. If successfully imple- mented on a national level, such programs may have a dramatic effect on the number of minority students entering the profession. The direct financial and experiential support provided to MILIS interns serves to increase the number of minority librarians. Additionally, the increased visibility of the library on campus resulting from the MILIS program as well as librarianship itself may attract other minority students to consider career options within the field.

If there is a need for more minority librarians then it is time for the profession to provide the support necessary to build up applicant pools. There may be other ways of accomplishing the same results but the MILIS program has the benefit of being easy to administer at a relatively low cost. Randall has stated that "perhaps the key factor in the success rate of recruiting racial and ethnic minorities into library and information science programs is the degree to which financial aid is

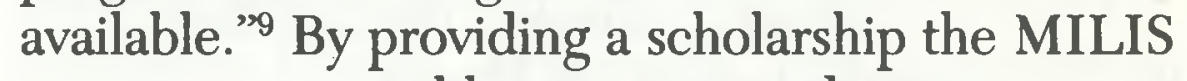
program may enable minority students to pursue graduate studies which they otherwise may not have been able to afford. Furthermore, the internship component of the program provides a student with an experience working in an academic library that is more substantial than the traditional student assistant job. Finally, the Mentoring component of the program may result in relationships that last throughout a professional lifetime.

\section{Appendix A}

Fall Semester Syllabus: Cataloging

\section{Week}

1-20 Overview of internship program.

Organization of the University Libraries.

Introduction to theory of cataloging. Bibliographic and authority searching. Introduction to OCLC and RLIN.

$3 \quad$ Main entry and call numbers (mostly literature).

4 Descriptive cataloging (Fields 250504) excluding serials.

$5 \quad$ Series no record kept and added entries in their two possibilities (Fields 440, 490, 830).

6-7 Subject cataloging. 8 Added entries (700 fields).

${ }^{9}$ Ann Knight Randall, "Minority Recruitment in Librarianship," in William E. Moen and Kathleen M. Heim, eds., Librarians for the New Millenium (Chicago: American Library Association, Office for Library Personnel Resources, 1988), 17. 


\section{Appendix B}

\section{Spring Syllabus: Reference}

Week

\section{3-11 Introduction to the Stony Brook} Library: A Self-Paced Workbook for LBR 150 (LBR 150 is a university course taught by reference librarians): reading and completing review questions.

3-6 Observing at the reference desk.

Overviews of Documents, Maps, Microforms, Interlibrary Loan, database searching and bibliographic instruction given by appropriate librarians.

3 Library of Congress Subject Headings.

Serials holdings list and Long Island Union List of Serials.

Reference desk procedures.

4 Reference use of OCLC and RLIN.

CD-ROMs located in the Reference Room.

\section{Off-campus library services conference-presenters alert}

The Central Michigan University Libraries and CMU's Extended Degree Programs and Credit Courses is sponsoring its fifth conference for the reporting, examination, and discussion of issues surrounding the provision of library services to students taking courses away from their central campuses, corporations or other institutional training sites. The conference will be held in Albuquerque, New Mexico, October 30-November 1, 1991. International in scope and participation, previous conferences have attracted American, Canadian, British and Australian librarians, college and university faculty, administrators and government officials.

Proposals for presentations including papers, panel discussions, and workshops are sought for such topics as: program planning/ needs assessment; student, faculty, and administrative services; information access and delivery; library user education; uses of technology; copyright, accreditation/licensure; internal/external marketing; interinstitutional cooperation/ resource sharing; sources of external funding; and grant proposal writing.

Persons interested in participating in the program are invited to send a titled proposal, an abstract of not more than 500 words describing the presentation and its delivery format, and a biographical statement of approximately 50 words for each presenter by November 15, 1990. Send proposals to (or for more information) contact: Virginia Witucke, Off-campus Library Services, Central Michigan University, 8550 Lee Highway, Suite 125, Fairfax, VA 22031-1515; (703) 849-8248.

\section{Copyright update}

The ACRL Copyright Committee is planning a program on the development and implementation of in-house library copyright policies. If your library has such a policy, please send a copy, along with a brief description of its development and applications, to one of the following Committee members:

Deborah Fairbanks, Acquisitions Department, University Libraries, University of Florida, Gainesville, FL 32611; (904) 392-0355; fax, (904) 392-7251. Cheryl LaGuardia, Reference Department, University of California Library, Santa Barbara, CA 93106; (805) 893-4316; fax, (805) 893-4676. 